Rafał Świecki

UNIWERSYTET ŁÓDZKI

\title{
Powstanie i rozwój horroru - kino nieme i początki kina dźwiękowego
}

Za pierwszy oficjalny horror uznaje się Studenta z Pragi Stellana Rye. Jego premiera miała miejsce 22 sierpnia 1913 r. w Berlinie. Zanim jednak przejdziemy do omówienia tego dzieła, cofnijmy się trzy lata wstecz, do roku 1910. Jeszcze w epoce kina jarmarcznego ${ }^{1}$ powstał film, który przyciagnął uwagę krytyków i do dzisiaj jest białym krukiem kina grozy. Mam tu na myśli Frankensteina, wyprodukowanego przez studio Thomasa Edisona. Trzeba tu mieć na uwadze, że adaptacje największych dzieł literatury grozy miały się świetnie w początkach kina, w związku $z$ tym nie dziwi taki wysyp tytułów. Na samym motywie Fausta Goethego powstało 12 filmów, i to tylko w latach 1896-1911.

Film Jamesa Searle'a Dowley'a, który uważał się za pierwszego reżysera filmowego, nie zaskakuje w warstwie fabularnej, w końcu to dość wierna adaptacja książki Mary Shelley, reżyser natomiast proponuje kilka ciekawych rozwiązań technicznych. Warto zwrócić uwage na to, że sceny w filmie sa nakręcone $z$ użyciem różnych filtrów. I tak, sceny $z$ założenia pełne grozy, takie jak np. narodziny Monstrum, sa zrobione $\mathrm{w}$ tonacji sepii i ciemnego brazu, a sceny radosne, np. spotkania Frankensteina $z$ narzeczona, w kolorach jasnych i mocno oświetlonych. Cieszy oko także scena powstawania potwora, gdzie wykorzystano taśmę puszczona od tyłu, a także scena $z$ lustrem, gdzie kamera pokazuje wchodzącego do pokoju potwora $\mathrm{w}$ lustrze oraz siedzacego $\mathrm{w}$ fotelu naukowca. Niby nic,

1 Nie wszyscy wiedzą, że jedne $z$ pierwszych horrorów na świecie powstawały również... w Japonii. W epoce kina eksperymentalnego najbardziej wyróżniły się Shinin no Sosei oraz Bake Jizo, powstałe jeszcze w XIX w. i gdyby nie późniejsze dzieje historyczne, Kraj Kwitnącej Wiśni mógłby poważniej zaistnieć na scenie kina grozy. 
ale jak na standardy tamtych czasów był to znak kunsztu reżyserskiego. W tym i w dużej części filmów niemych widać zarówno wpływ literatury romantycznej, jak i teatru. Frankenstein przystępuje tu do eksperymentu $z$ czystymi intencjami, lecz $\mathrm{w}$ trakcie w jego serce wkrada się zło i pycha, nie dziwi więc wynik końcowy. Sama teatralność aktorów będzie dla wielu wada, ale po raz kolejny wypada mieć na względzie czasy, o których mowa.

Frankenstein zrealizowany został trzy lata przed oficjalnymi narodzinami horroru - powstaniem Studenta z Pragi. Film Stellana Rye jest adaptacja Fausta Goethego i opowiada historię Balduina, młodego studenta, który ratując pewnego dnia hrabiankę Margit przed utonięciem, zakochuje się w niej. Niestety, jest zbyt biedny, żeby zdobyć jej serce, sprzedaje więc tajemniczemu Scapinelliemu swoje odbicie w lustrze za 100 sztuk złota i powodzenie w życiu. Scapinelli oczekuje od Balduina tylko jednego - jego własnego odbicia w lustrze. Student, nie widząc w tym nic złego, podpisuje dokument i od tego właśnie momentu traci odbicie, które zaczyna żyć własnym życiem, co rujnuje Balduina. Film Duńczyka można podziwiać za kilka rzeczy. Przede wszystkim wprowadził do kina coś, co zwłaszcza w kinie niemieckim, dojrzewało, żeby w końcu zalśnić m.in. u Fritza Langa, czyli motyw fatalnej dwoistości ludzkiej natury, której nie można się pozbyć, a która czyni człowieka nieszczęśliwym. Kilka scen szczególnie zapada w pamięć, np. scena wychodzenia odbicia Balduina $z$ lustra czy scena gry w karty $z$ sobowtórem.

W filmie po raz pierwszy zalśniła gwiazda Paula Wegenera ${ }^{2}$, jednego $\mathrm{z}$ największych aktorów kina niemego. Zagrał w ponad 70 filmach, najbardziej jednak zapamiętano jego rolę w Golemie z 1915 (film zaginą) i 1920 r. (remake filmu z 1915 r.). Golem to opowieść rozgrywająca się w Pradze. Uczony rabin Loewe wypatruje w gwiazdach przyszłości narodu żydowskiego, który czeka klęska. Próbuje jakoś temu zapobiec, powiadamiając innych, jest jednak za późno, ponieważ rycerz Florian został już wysłany przez Imperatora $z$ dekretem nakazującym Żydom opuszczenie getta $z$ powodu uprawiania czarnej magii i kontaktów $z$ Szatanem. Loewe prosi Imperatora o audiencję, na co ten się zgadza pod warunkiem, ze rabin będzie zabawiał go magicznymi sztuczkami. Loewe tworzy więc strażnika, który ma chronić naród żydowski przed zagrożeniami. Golem wymyka się spod kontroli i zaczyna siać chaos w okolicy... Film jest

2 http://www.imdb.com/name/nm0917467/?ref_=nv_sr_1 [data dostępu: 16.12.2013]. 
piękny - ze znakomitą muzyką i dekoracjami (realizowany w żydowskim getcie w Pradze) oraz dobra gra aktorska, jednym ze znaków przemiany, jakiej zaczyna w tym momencie ulegać kino, odsuwajacc teatralne korzenie. Ciekawy jest fakt, że w filmie gra Lyda Salmonova, żona Wegenera.

Rok 1920 to przełom, narodziny nurtu, który dominował w późniejszym kinie przez wiele lat - ekspresjonizmu niemieckiego, czyli świadomej deformacji rzeczywistości, kreowanej na koszmar senny, pełen krzywizn i załamań. Dodatkowo pomagała tu czarno-biała sceneria filmów. Reżyserzy bardzo często sięgali w związku z tym po opowieści niesamowite, zawsze przyprawiane aura tajemniczości i niepokoju. Największymi przedstawicielami nurtu ekspresjonistycznego sa Fritz Lang ${ }^{3}$ i Friedrich Wilhelm Murnau, jednak zanim przejdę do filmów tych twórców, chciałbym poświęcić chwilę uwagi obrazowi, który rozwinał ten nurt i aż do dzisiaj jest uważany za naprawdę przerażający, mianowicie mam na myśli Gabinet doktora Caligari Roberta Wiene'a ${ }^{4}$. Do miasteczka przybywa wędrowny hipnotyzer razem ze swoim medium, Cesarem, który jest somnambulikiem. Wkrótce w mieście zaczynaja ginać ludzie. Przyjaciel jednego $z$ zabitych, Francis, rozpoczyna własne dochodzenie i odkrywa, że hipnotyzer jest reinkarnacją mrocznego doktora Caligari, który używa swojego medium do popełniania zbrodni. Film jest fantastyczny - scenerie sa świetne, muzyka znakomicie oddaje nastrój panujaccy na ekranie, a kreacje zarówno Cesara, jak i Caligariego zasługują na najwyższe uznanie. Nic więc dziwnego, że na początku lat 30. film ten przerażał widzów. Gabinet... miał tak duży wpływ na kinematografię, że aż do lat 70., czyli do czasu fali kina gore, twórcy posługiwali się językiem tego obrazu.

Rok 1921 to Zmęczona Śmierć Langa - opowieść o nieuchronności śmierci, poprowadzona w czterech odrębnych historiach, a 1922 r. to Nosferatu - symfonia grozy Murnaua. Film jest adaptacja dzieła Brama Stokera, Drakula. Problemem Murnaua był brak praw autorskich, w zwiazku $z$ tym wymuszono na twórcach zmiany w scenariuszu. Zmiany dotyczyły w gruncie rzeczy tylko nazw

3 Do Langa należy nieco zapomniany już obraz, jeden $z$ pierwszych balansujacych na granicy kina grozy i science fiction, czyli Metropolis (1927) - film będący niedocenionym w swoim czasie arcydziełem niemieckiego ekspresjonizmu. Zauważony dopiero w latach 80 . XX wieku, kiedy odkryto w filmie realne przepowiednie przyszłości. Zob. http://horror.com.pl/publicystyka/art.php?id=81 [data dostępu: 16.12.2013].

4 Odsyłam do klasycznej już pracy Kracauera - zob. S. Kracauer, Od Caligariego do Hitlera, Warszawa 1958. 
i imion, historia pozostała prawie niezmieniona. Jednocześnie film daje nam to, za co kochamy horrory dzisiaj: znakomicie ucharakteryzowanego głównego bohatera (o samym odtwórcy, Maxie Schrecku, krażyły legendy. Jego współpracownicy twierdzili, że jest wampirem. Miłośnicy tej legendy ${ }^{5}$ utrzymywali, że podczas kręcenia Schreck ani razu nie zamrugał powiekami, a w scenie powstawania $z$ trumny miał wstać pod idealnym kątem prostym - w rzeczywistości posłużyła mu do tego sprężyna), cudownie nakręcone sceny grozy i atmosferę terroru, która nie opuszcza nas przez cały film. Obraz ten został uznany za pierwsze arcydzieło gatunku, a legenda o filmie rozwinęła się do tego stopnia, że w filmie z 2000 r. pod tytułem Cień wampira, Schreck (którego grał William Dafoe) został faktycznie pokazany jako wampir wysysający krew z członków ekipy. Rewelacyjne zabiegi techniczne (gra cieni jest znakomita) gruntownie przyczyniły się do stworzenia niesamowitej atmosfery obrazu. Rok 1922 przyniósł jeszcze jeden z zapomnianych obrazów grozy: Haxan, opowiadajacy o czasach inkwizycji (akcja filmu dzieje się pod koniec XV w.), który choć nie straszy tak, jak Nosferatu, wart jest obejrzenia ze względu na ciekawe ujęcie tamtych mrocznych czasów.

Horror kontynuował dominację w kinie niemym, a w 1925 r. powstał Upiór $w$ operze, w którym wystapił Lon Chaney - jedna $z$ ikon kinematografii, zwłaszcza tej poświęconej horrorowi, nazwany „człowiekiem o tysiącu twarzach”. Był mistrzem charakteryzacji, posiadał własny zestaw do tego celu i zatrzymał sekrety warsztatu aż do śmierci. Obecnie ten słynny zestaw znajduje się w Los Angeles County Museum - został tam przekazany przez żonę aktora trzy lata po jego śmierci. A jego śmierć była dość kuriozalna, bowiem podczas kręcenia Błyskawicy w 1929 r. nabawił się zapalenia płuc, choroby dość trudnej do leczenia w tamtych czasach. Niedługo potem zdiagnozowano u niego raka płuc. Mimo intensywnej terapii nie udało się uratować aktora, a jego śmierć pograżyła w żałobie cały filmowy świat. Kochano go tak, że podczas pogrzebu US Marine Corps pełnili wartę honorowa przy jego krypcie, która znajduje się w Forest Lawn Memorial Park Cemetery w Glendale w Kalifornii. Pozostała ona nieoznaczona. Jego syn, Creighton Tull Chaney (znany jako Lon Chaney Jr.), kontynuował dziedzictwo ojca,

5 Schreck zagrał w ponad 40 filmach, co pozwala skutecznie obalić wszelkie mity dotyczace jego postaci. Pokazuje to również wpływ osobowości aktora na ekipę filmową i pozwala zaobserwować pierwsze „nakręcanie” publiczności (mistrzowsko zrealizowane przy okazji kampanii reklamowej Blair Witch Project). 
ale aktorstwem zajął się dopiero po jego śmierci. Jego ikoniczna i najbardziej rozpoznawalna rola była kreacja wilkołaka w The Wolf Man (1941). Poza tym jest jedynym aktorem, który zagrał wszystkie cztery sztandarowe potwory studia Universal: Wilkołaka, Mumię, potwora dr. Frankensteina (w filmie Duch Frankensteina) oraz syna Draculi w filmie o tym samym tytule $z 1943$ r. Zmarł na atak serca w wieku 67 lat w roku 1973.

No właśnie - Universal. To studio, które na początku kina dźwiękowego zdobyło dominująca pozycję w świecie filmowym, wiodło prym zwłaszcza w horrorach, dając nam wspomniane wcześniej potwory. W 1931 r. ukazały się dwa najbardziej znane i po czasy obecne uwielbiane i docenianie filmy studia: Drakula oraz Frankenstein. Universal pomógł dotrzeć na szczyt dwóm wielkim aktorom: Beli Lugosiemu i Borisowi Karloffowi. Ten ostatni, którego prawdziwe nazwisko brzmi William Henry Pratt, nazwany później nawet „Karloffem niesamowitym”, największą sławę zdobył dzięki roli monstrum w Frankensteinie. Pomimo grania w swoich filmach głównie czarnych charakterów, poza planem miał opinię miłego dżentelmena, który znany był ze współpracy $z$ organizacjami dobroczynnymi. Ponadto był pierwszym aktorem, który do kontraktu dołaczył klauzulę o tym, że czas charakteryzacji ${ }^{6}$ będzie doliczany do jego gaży. Aktor żenił się sześć razy, ale urodziła mu się tylko jedna córka, Sara Karloff. Podobno aktor miał opuścić plan zdjęciowy Syna Frankensteina i w pełnej charakteryzacji pognać do szpitala. Zmarł 2 lutego 1969 r., przeżywszy 82 lata.

Rolę monstrum proponowano Lugosiemu, lecz ten po sukcesie Drakuli stwierdzil, że jest zbyt przystojny do grania potwora, poza tym niema rola nie przystawała takiej gwieździe (jak sam twierdził). Krąży anegdota, że gdy James Whale, reżyser filmu, spotkał w barze Karloffa i zaproponował mu rolę potwora, aktor był oburzony: „w końcu wyglądałem całkiem elegancko" - miał powiedzieć. W filmie sa dwie kontrowersyjne sceny. Pierwsza $z$ nich była scena, w której Frankenstein po stworzeniu potwora mówi: „To żyje, to żyje! Teraz nareszcie wiem, jak to jest być bogiem!". Miało to urazić uczucia religijne widzów. Druga scena, która wywołała prawdziwe oburzenie, był moment, w którym potwór bawi się $z$ małą dziewczynką i nieświadomie topi ją w jeziorze.

${ }^{6}$ W przypadku Frankensteina nałożenie make-upu trwało ponad 3 godziny, tyle samo zdjęcia. Podczas kręcenia Mumii charakteryzacja granej w dwóch scenach przez Karloffa mumii trwała aż 8 godzin. Aktor cierpliwie to znosił, a jego poświęcenie stało się jego znakiem firmowym przez resztę kariery. 
No i wreszcie Drakula Toda Browninga, dzięki której Bela Lugosi wzniósł się na wyżyny sławy. Dużą rolę w jego sukcesie odegrała genialna kreacja księcia, co w gruncie rzeczy Lugosi zawdzięczał temu, że jako węgierski emigrant długo nie mógł nauczyć się języ$\mathrm{ka}$, w zwiąku z czym uczył się swoich kwestii fonetycznie, co dało fantastyczny efekt. Jego pierwsze spotkanie $z$ Renfieldem to absolutne mistrzostwo w budowaniu napięcia, a słowa „I... AM Dracula" oraz „I never drink... wine” to jedne $z$ najsłynniejszych kwestii, jakie padły w horrorze. Sam Lugosi (w zasadzie Bela Blasko, który nazwisko sceniczne przyjął od nazwy miasteczka, w którym się urodził - Lugos ${ }^{7}$ ) dostał rolę Drakuli dzięki śmierci Chaneya, któremu pierwotnie ją zaproponowano. Różne opinie dotyczyły jego relacji z Karloffem, z którym Węgier współpracował przy kilku produkcjach, m.in. w Synu Frankensteina. Jedni mówili, że Lugosi nie znosił Anglika, zazdroszczac mu większych ról, jakie dostawał, inni znowu twierdzili, że w tych czasach byli dobrymi przyjaciółmi. Sam Karloff powiedział, że $z$ początku Lugosi był dość nieufny, bał się, że Anglik będzie chciał przyćmić jego grę aktorską. Gdy okazało się to nieprawda, Lugosi miał polubić Karloffa i od tej pory ze soba współpracowali. Chociaż później komentowano, że Lugosi bardzo denerwował się na Karloffa, gdy ten żądał... przerw na popołudniową herbatę. Lugosi cierpiał, ponieważ Universal wolał obsadzać w swoich filmach właśnie Karloffa i przeżywał kryzys artystyczny. Jego uzależnienie od morfiny i metadonu tylko pogłębiło kryzys. Pogłębiło go do tego stopnia, że przy tworzeniu pastiszu filmów o potworach $z$ udziałem znanych postaci slapstickowych, Abbotta i Costello (Bud Abbott, Lou Costello Meet Frankenstein), twórcy filmu myśleli nawet, ze Lugosi nie żyje i chcieli dać rolę Drakuli Ianowi Keithowi. Ten film był ostatnia wysokobudżetowa produkcja z udziałem Lugosiego. Później odnalazł go w biedzie Ed Wood (znany jako najgorszy reżyser wszech czasów, choć myślę, że Uwe Boll mógłby się obruszyć), który dał mu kilka ról w swoich filmach. Uzależnił się od demerolu. Zmarł 16 sierpnia 1956 r. w wieku 73 lat na atak serca. Pochowano go w pelerynie Drakuli. Co ciekawe, oryginalna peleryna $z 1931 \mathrm{r}$. przetrwała i jest w posiadaniu studia Universal.

Następne lata to czas sequeli popularnych filmów grozy. Temat został wyeksploatowany do granic możliwości, powstawały jednak perełki, stojące gdzieś obok gigantów kina, np. Pies Baskervillów

7 Warto zapoznać się $z$ biografia jednego $z$ najbardziej interesujacych aktorów tamtych czasów: http://en.wikipedia.org/wiki/Bela_Lugosi [data dostępu: 16.12.2013]. 
(1939) czy Doktor Jekyll i pan Hyde (1931). II wojna światowa przyniosła ze sobą nowy rodzaj zniszczenia - bombę atomowa, a w kinie rozpoczęła się nowa epoka - epoka monster movies ${ }^{8}$.

\section{Bibliografia}

Kracauer S., Od Caligariego do Hitlera, Warszawa 1958.

Rodan P. J., Polski horror, czyli kilka słów o filmie grozy, Łódź 2008.

http://en.wikipedia.org/wiki/Bela_Lugosi [data dostępu: 16.12.2013].

http:// horror.com.pl/publicystyka/art.php?id=81 [data dostępu: 16.12.2013].

www.imdb.com/name/nm0917467/?ref_=nv_sr_1 [data dostępu: 16.12.2013].

\section{Filmografia}

Bud Abbott, Lou Costello Meet Frankenstein, reż. Ch. Barton, 1948.

Cień wampira, reż. E. E. Merhige, 2000.

Dr. Jekyll and Mr. Hyde, reż. R. Mamoulian, 1931.

Dracula, reż. T. Browning, K. Freund, 1931.

Duch Frankensteina, reż. E. C. Kenton, 1942.

Frankenstein, reż. J. S. Dowley, 1910.

Frankenstein, reż. J. Whale, 1931.

Gabinet doktora Caligari, reż. R. Wiene, 1920.

Golem, reż. P. Wegener, H. Galeen, 1915.

Haxan, reż. B. Christensen, 1922.

Nosferatu - symfonia grozy, reż. F. W. Murnau, 1922.

Pies Baskervillów, reż. S. Lanfield, 1939.

Student z Pragi, reż. S. Rye, 1913.

Syn Draculi, reż. R. Siodmak, 1943.

Syn Frankensteina, reż. R. V. Lee, 1939.

The Wolf Man, reż. G. Waggner, 1941.

Upiór w operze, reż. R. Julian, E. Sedgwick, E. Laemmle, L. Chaney, 1925.

Zmęczona Śmierć, reż. F. Lang, 1921.

\section{Abstract}

The aim of the article is to reconstruct the history of horror, which includes the creation of the genre and its development in the silent cinema until a sound film. The author discusses the few productions of this period, looking at the dominant themes and the formal side, directing his attention to an interesting technical solutions. He writes about: Student $z$ Pragi, Frankenstein, Dracula and Gabinet doktora Caligari.

Key words: horror, history of movie, vampire, expressionism.

8 Iście groteskowy gatunek filmowy, w którego obszarze mieszczą się filmy o zmutowanych mrówkach, pająkach czy... gigantycznych amebach. 